WORLD CONGRESS ON OSTEOPOROSIS, OSTEOARTHRITIS AND MUSCULOSKELETAL DISEASES

\title{
VIRTUAL CONGRESS
} August 26-28, 2021
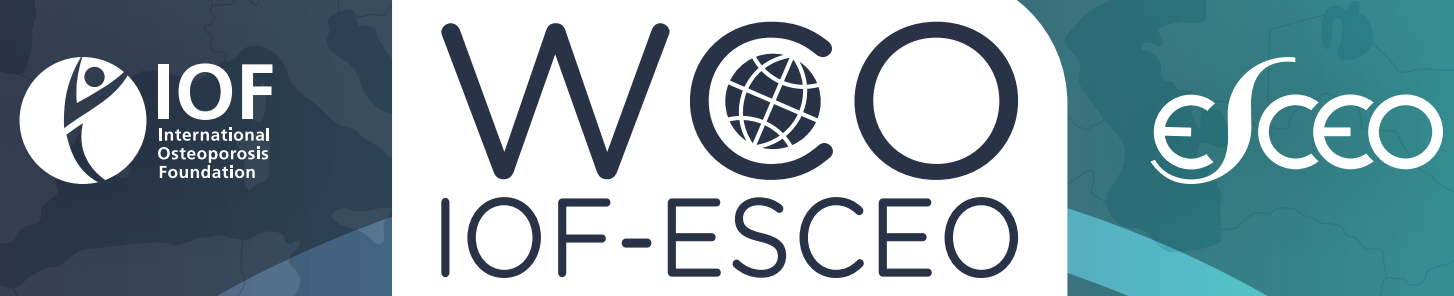

\section{VIRTUAL}

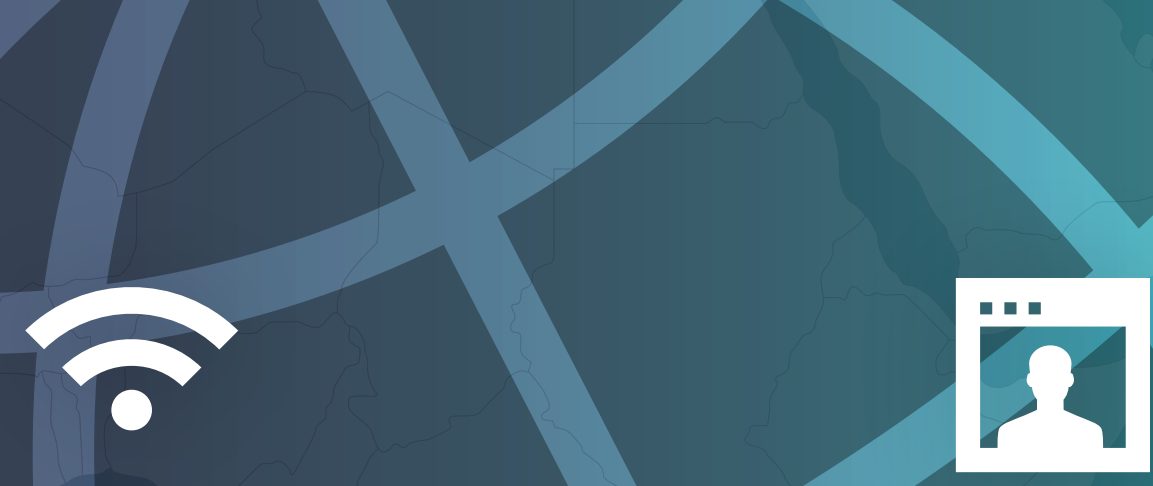


P568

ASSESSMENT OF THE MAIN INDICATORS OF

THE HEMOSTASIS SYSTEM IN PATIENTS WITH

RHEUMATOID ARTHRITIS

K. V. Zhigulina ${ }^{1}$, S. S. Spitsina ${ }^{2}$

${ }^{1}$ City Clinical Emergency Hospital 25, ${ }^{2}$ Federal State Budgetary Institution "Research Institute of Clinical and Experimental Rheumatology A.B. Zborovsky"; Volgograd State Medical University, Volgograd, Russia

Objective: To assess the main indicators of blood coagulogram in patients with rheumatoid arthritis (RA), to determine their relationship with the degree of activity, duration and systemic manifestations of the disease.

Methods: 100 patients with RA were examined. The state of the blood coagulation system was determined according to the following indicators: prothrombin index (PTI) according to Quick (\%), fibrinogen $(\mathrm{g} / \mathrm{l})$, activated partial thromboplastin time (APTT, $\mathrm{s})$, international normalized ratio (INR).

Results: Among the surveyed there were $76 \%$ of women and $24 \%$ of men. The average age of the patients was $53.7 \pm 12.25 y$, the duration of the disease was $6.13 \pm 3.69 \mathrm{y}$. Seropositive RA was detected in $63 \%$. All patients had moderate to high RA activity (32\% and $68 \%$ ). Pathology of the cardiovascular system was detected in $84 \%$ of patients. More significant changes in the coagulogram were recorded in patients with systemic manifestations and concomitant cardiac pathology compared with the articular form: increased PTI $(107.20 \pm 1.26 \%$ and $103.68 \pm 3.21 \%$, respectively) and fibrinogen $(6.4 \pm 0.8 \mathrm{~g} / \mathrm{l}$ and $5.1 \pm 0.76 \mathrm{~g} / \mathrm{l})$; decrease in INR $(0.83 \pm 0.06$ and $0.96 \pm 0.14)$ and APTT $(27.5 \pm 1.21 \mathrm{~s}$ and $34.1 \pm 2.4 \mathrm{~s}$ ). The same trend persisted in the group of patients with a disease duration of $>7 \mathrm{y}$. Correlation analysis between coagulogram parameters and disease activity showed a direct positive relationship between IPT and ESR $(r=+0.23)$, fibrinogen and ESR $(r=+0.34)$, fibrinogen and CRP $(r=+0.32)$. Also, inverse correlations were obtained between INR and ESR $(r=-0.24)$, APTT and ESR $(r=-0.22)$, APTT and CRP $(r=-0.26)$.

Conclusion: In RA patients, an increase in PTI and fibrinogen level, a decrease in INR, and a shortening of APTT were found, which indicates activation of the blood coagulation system, hypercoagulation. The revealed disorders correlate with RA activity, disease duration, presence of systemic manifestations and concomitant cardiovascular pathology.
P569

\section{CARBOHYDRATE IMBALANCE IN PATIENTS WITH GOUTY ARTHRITIS \\ K. V. Zhigulina ${ }^{1}$, S. S. Spitsina ${ }^{2}$}

${ }^{1}$ City Clinical Emergency Hospital 25, ${ }^{2}$ Federal State Budgetary Institution "Research Institute of Clinical and Experimental Rheumatology A.B. Zborovsky"; Volgograd State Medical University, Volgograd, Russia

Objective: To study the incidence of carbohydrate metabolism disorders in patients with gouty arthritis (GA).

Methods: The study included 40 patients with primary chronic GA, diagnosed on the basis of $\mathrm{S}$. Walles criteria and with impaired carbohydrate metabolism. Among the examined men prevailed $(65 \%)$, the average age of the patients was $52 \mathrm{y}$. A family history of gouty arthritis was observed in 25 patients. The average duration of the disease was $8.2 \pm 3.5 \mathrm{y}$. All patients underwent daily fasting measurements of blood sugar levels with a glucometer, and a study of glycosylated hemoglobin was carried out.

Results: All patients were hospitalized in the rheumatology department. The onset of GA was observed on average at $35.6 \pm 10.0$ y. Tofus form was diagnosed in $26(65 \%)$ patients, $14(35 \%)$ did not have tophus. The average level of fasting blood glucose is $8.4 \pm 2.8 \mathrm{mmol} / \mathrm{l}$. Type 2 diabetes mellitus had $10(25 \%)$ patients. In $25(62.5 \%)$, impaired glucose tolerance was noted. Impaired fasting glucose was observed in $5(12.5 \%)$ patients. The average level of glycosylated hemoglobin was $7.0 \pm 1.5 \%$. At the time of examination, $8(20 \%)$ were receiving hypoglycemic therapy. In the course of the study, complications of diabetes mellitus were identified. Diabetic retinopathy was most often detected in 6 (15\%) patients; nephropathy at the stage of microalbuminuria was detected in $5(12.5 \%)$ patients.

Conclusion: The study revealed a fairly high prevalence of carbohydrate metabolism disorders in patients with gouty arthritis. Careful monitoring of both the course of gout and its inherent comorbid pathology is necessary due to the numerous complications and concomitant disorders. 